VOL 2 (2018) NO 4 - 2

e-ISSN : 2549-9904

ISSN : 2549-9610

INTERNATIONAL JOURNAL ON INFORMATICS VISUALIZATION

\title{
A Paradigm Shift on the role of CIO's in Cloud and IOT based Organizations
}

\author{
Jipson George Thoomkuzhy\#, Dr. Mohammed Nazeh ${ }^{\#}$ \\ \# Limkokwing University of Creative Technology, Malaysia \\ E-mail: Jipsongeorge2000@gmail.com, mohammed.nazeh@limkokwing.edu.my
}

\begin{abstract}
Cloud computing and IOT has transformed the way organizations across industries work. This review paper researched the role of the global CIO regarding their key employment capacities and their basic abilities and competencies which are required all together for a CIO to accomplish unrivaled hierarchical execution of the future business condition. The discoveries of this review will give insight to five key employment capacities and the basic competencies which we accept are fundamental to the role of the global CIO in the present and future business condition. The discoveries will additionally show that the global CIO role is winding up progressively and is key in driving development, hierarchical change and technological change. Consequently, the global CIO should be a visionary vital leader with eminent relational abilities and business keenness and the capacity to team up evenly over the central business capacities and with key business accomplices. About Six CIO interviews directed by the CIO Executive Council were investigated and reviewed as far as past journals which had recognized various key employment capacities and basic abilities and competencies for the role of a global CIO.The role of the Chief Information officer (CIO) has turned out to be progressively testing and mind-boggling as data correspondences innovation has turned out to be essential for most organizations. To date, there has been little research which has exactly inspected the roles and the basic competencies of the global CIO. An online overview of CIOs affirmed the significance of CIO competencies and highlighted the basic ones. An arrangement of the basic competencies of CIOs was analyzed in this review. The key discoveries demonstrate that the role of the global CIOs has progressed toward becoming progressively business engaged and vital in cloud and IOT based organizations. Eventually, how a CIO leads and deals with his/her ICT staff will enormously impact how effective a CIO is in the role. Be that as it may, the CIO still requires the knowledge of key innovation skills so, individual information or access to additional abilities is also essential in their role
\end{abstract}

Keywords - CIO, Chief Information Officer, CIO competencies, Cloud computing, IOT.

\section{INTRODUCTION}

The abilities and competencies that served the CIO (chief information officer) well in the past are probably going to be essential however, it is lacking for future progress. The advances in education and learning of a CIO role seem to be the most unique element of progress since its commencement about four decades ago. This position is developing from an attention on Information management to an emphasis on innovation administration and organizational advancement. With these changes, the CIO cannot bear the cost of just reacting to demands any longer; however, they should proactively work to catch openings that drive the organization's fortunes in line with mission and vision of the organization.

Notwithstanding, the dynamic part of the CIO and the IT (information technology) organization itself must adjust to the new conditions in business and technology. Standard hierarchical outlines around advancements or different facilities may not work well for all the organizations. IT authoritative structures in light of procedures will be lither and better situated to proactively use open means for meeting the scholastic and business needs of the organization (Patidar, Rane \& Jain, 2012). This review thus takes a forward-looking perspective into the CIO role, recognizing basic abilities and skills required for key organizations in 2012 and past years in view of a writing survey, discussions and quantitative contribution from current IT professionals. Top contemplations for organizing IT to give organizational help in the 2020s are additionally talked about. On the long run, some inventive parts for the $\mathrm{CIO}$ in the "new typical system" are distinguished.

The CIO's capacity to lead an organization that gives frameworks of unwavering quality and dependability, is an essential role for organizations. Basic abilities attributed to CIOs entail the improvement of a vital organizational correspondence and skills abilities, the capacity to work together viably to use shared requirements and assets, operational administration aptitudes, and an expansive knowledge of information technology, administrative, and 
legal issues of the organization (Hay, Nance \& Bishop, 2010).H. David Lambert tended to "The Changing Role of the CIO" in an introduction at the 2009 EDUCAUSE Annual Conference in Denver, Colorado.

The role of a CIO currently affects the whole organization. Confirming the basic aptitudes featured in the 2009 EDUCAUSE Release Brief, Lambert set out the accompanying basic capabilities for the future CIO are:

- Comprehensive understanding of innovation ideas and standards

- A wide comprehension of the advanced learning and its supporting procedures

- Advanced abilities in venture administration

- Enjoyment of the difficulties related with activities and management. As the CIO's role grows to cover all parts of the organization, CIOs will be progressively tested to adjust countervailing weights and parts. An ongoing IBM investigation of about 2,600 CIOs around the globe in an assortment of divisions encourages CIOs to get ready for these integral roles:

- A wise visionary, and a capable realist

- A shrewd esteem maker, and a steady cost shaper

- A communitarian business pioneer, and a moving IT supervisor

- The IBM survey calls attention to that few of similar abilities and capabilities that Lambert and others specify are fundamental for progress:

- A solid comprehension of the association's most squeezing issues

- The capacity to impart the estimation of advancement

- The improvement of visionary designs

- The capacity to use joint effort and associations

- The capacity to catch hierarchical openings

- Agility

- The capacity to deal with social opposition

For the CIO, this likewise makes some non-traditional parts: filling in as the organizations change specialist and as an empowering influence of authoritative adaptability. It is getting to be clearer that the CIO's role is "less about innovation and more about strategy."

\section{RESEARCH PROBLEM}

\section{Problem-1}

The critical competencies required for the $\mathrm{CIO}$ role in a global context for cloud \& IoT based organizations are not identified yet. It was said following the 2000 convergence that, "throughout the following five years, the IT capacity will progressively come to be esteemed for its special point of view on both the organization and innovation and its capacity to utilize this viewpoint to encourage system improvement and prepare technological procedures."

However, the 2005 gathering additionally noticed a couple of provisions about this new role. One was waiting doubt among numerous officials about the estimation of IT.
Officials were careful about giving IT unconditional authority, as had occurred before. In this manner, despite the fact that IT was perceived as basic to the business' survival, the IT administrators of 2005 still confronted some believability issues around the vital utilization of IT. In looking to 2010, the 2005 gathering anticipated IT's contribution in technique proceeding, however in an undeniably incorporated design. "Previously, business and IT have had parallel existences; now we need to work all the more firmly together," said one director. "The divider must be expelled," said another. All concurred that business system will turn out to be more liquid and IT basically should partake in its advancement. "We should be in steady correspondence and transaction about procedure," they concurred. To put it plainly, technique advancement and execution for both business and IT will end up being a community push to convey endeavor esteem. "Today, we are activating IT to help business procedure; tomorrow we will assemble the business through utilizing IT," said a member. IT's part will move from technique activation to procedure joint effort.

Regardless of these, the 2005 members noticed that IT was progressively being perceived for its capacity to change over methodology without hesitation. "We are an impetus for procedure assembly and business improvement," clarified one part. The expanding interconnectedness of business and IT implied that the lines amongst business and IT methodology, and their execution, were obscuring. System was coming to be perceived not only for what it was but rather for how well it was executed. With all associations approaching a similar equipment and software, aggressive separation originated from how they were used. Looking to 2010, the 2005 gathering anticipated this structural approach quickly turning into the overwhelming IT administration style. Similar standards basic the past engineering work in equipment and software will be connected to a scope of business tasks.

IT's logical capabilities joined with more noteworthy business learning will progressively enable a business to comprehend its data and procedures, at that point designer them. Learning of the business will be an essential to adequately modeler an association.

Creating designs will be a key strategy for picking up business information inside IT. Thus, models will turn into the establishment on which IT helps the business to outline and execute methodology in a significantly more natural manner than before. Along these lines, numerous more kinds of engineering will be presented, and a considerable lot of them will be driven by IT, in conjunction with business accomplices. IT will turn out to be more componentized with the goal that it can be all the more viably oversaw and outsourced (where suitable). IT frameworks and procedures will turn out to be progressively architected. Associations will have the capacity to purchase modules of usefulness rather than huge applications. They will purchase bits of computing time rather than gigantic PCs.

To do as such, however, IT chiefs should better comprehend their own procedures, and how to isolate them, to exploit this more componentized world. The 2005 concentration gather expressed that technique expectation was as yet a fantasy. Most concurred that the occasions from 
2000 to 2005 showed that foreseeing what's to come was near unthinkable. Thus, the individuals from the 2005 concentration bunch had changed their way to deal with IT administration. As opposed to foresee the future, they expected to make IT more adaptable, through design, with the goal that IT could react all the more rapidly to business needs. All the concentration aggregate associations had specialized draftsmen who made innovation outlines to control them through plenty of specialized alternatives accessible.

With their goals set to target 2010, the 2005 convergence saw this pattern commence, trusting it would prompt IT to adopt more initiative duties. Administration would, in this way, turn into IT's predominant main focus as at year 2010.

"We see a genuine development in the requirement for initiative in IT," said one of the chief during one of their convergence. Others concurred that IT will stand up and embrace certain improvements.

"We will be viewed as approach producers and thought pioneers; while we will keep on providing innovation and data benefits, our esteem will originate from our consolidated authority of the venture with diverse organizations", said another member of the convergence in 2005. The convergence trusted that IT's point of view will wind up increased in value by the organization.

As one manager expressed, "The specialty units are great at outlining and actualizing specific procedures; our part will be to guarantee that these individual endeavors are at an advantage over the entire venture." Another anticipated, "I trust that we will turn out to be more entrepreneurial later on, stepping up with regards to giving authority in improving the organization."

The 2005 convention members also noticed that IT's function in organizational advancement was particularly at the forefront of their thoughts. "IT is exceptionally powerless against commoditization; we are, in this manner dependable on the pursuit for improvement," said one member. "This is a key focus for us," said another. IT advancement for business esteem positioned as the best IT challenge for the 2005 convergence. Previously, it has been restrained by the absence of organizational dexterity but today, it is gradually evolving."

\section{Problem-2}

As per Broadbent \& Kitzis, 2010, understanding the role of CIO in adaption \& implementation of cloud computing and IoT in relation with operational management role of CIO is still at infancy stage. The 'internet of things', IoT, the term that was first displayed by Kevin Ashton in 1998, is a destiny of Internet and ubiquitous computing. This inventive revolt addresses the destiny of accessibility and reachability. IoT tackles the commencement of Machine-to-Machine (M2M), yet not confined to it.

M2M implies correspondence between two computers or machines without any human intervention. In IoT, even nonrelated components can end up being an essential aspect of IoT; for example, a data giving contraption, like a scanner tag or a RFID tag, recognized through a device (Gubbi, etal. 2013). It is quite tasky to allow everything end up being a functionality of IoT and then later having each one of the benefits open through cloud computing. There lie a couple of issues that must be managed to allow CoT (cloud of things) win for the change of the world when all is said in done and humankind specifically. Other than data and resources, cloud needs to deal with the business point of view as well.

An organization's cloud computing and IOT requires a legitimate IT organization/administration model to ensure an anchored computing condition and to consent to all critically-leveled information advancement approaches. Along these lines, organizations require a game plan of capacities that are essential when suitably completing and supervising cloud and IOT organizations, including demand organization, relationship organization, data security organization, application lifecycle organization, risk and consistence organization. The ability to reduce capital hypothesis for computing resources, and rather, satisfy computational needs through operational expenses is ideal of for any cloud computing. Cloud computing and IOT can cut down the fundamental cost of operation and also condense the time required to get a favorable result from the hypothesis ( in this way better modifying expense to authentic usage (Khan, 2014). Nonetheless, the conventional techniques and approach an organization uses to obtain computational resources such as capital utilizations may be viably maintained at a strategic level of secrecy from a group or an individual, and the procuration obscured under regular assignments.As such, an ideal cloud-IoT implemented setting should be able to address certain elements, some of them include:

a) Consistence- One of the most generally perceived consistence issues rising against many organizations is about the consistency of their data territory. In other words, this could be said to mean the inaccuracy and imprecision of data or information emanating in an organization by virtue if the ever-changing nature if duties. Use of an in-house computing center empower organizations to structure its computing condition and to know in detail where data is secured and what shields are used to anchor the data. Inadequate data shield will help elevate data inconsistency and information error. In the present cloud based world, IT does not for the most part have full control over the provisioning, de-provisioning and undertakings of establishment. This has extended the inconvenience for IT to give the organization, consistence and risk organization required. To direct the distinctive risks and vulnerabilities in changing to the cloud, IT must alter its standard IT organization and control methodology to consolidate the cloud (Gartner, 2008).

b) Security- Security is a basic responsibility as far as cloud computing is concerned; there are different issues to be tended to if the cloud is to be perfectly secure. (Martin Muduva, 2015). As cloud computing is achieving extended unmistakable quality, concerns are being voiced about the security issues displayed through allotment of this new model. The practicality and efficiency of standard confirmation parts are being re-evaluated as the characteristics of this innovative course of action model can differentiate for the most part from those of traditional designs. An elective perspective on the topic of cloud security is this is anyway another, but wide, case of 
"associated security" and that equivalent security decides that apply in shared multi-customer concentrated server security models apply with cloud security.

The relative security of cloud computing organizations is an unruly issue that may concede its selection. Physical control and the ability to ostensibly survey data associations and access ports is required with a particular ultimate objective to ensure data joins are not exchanged off. Issues with the exception of the gathering of cloud computing are relied upon in broad part to the private and open divisions' unease including the outside organization of security-based organizations. It is the specific thought of cloud computingbased organizations, private or open, that progress external organization of gave organizations. This passes on amazing inspiring power to cloud computing pro associations to sort out gathering and keeping up strong organization of secure administrations.

A typical strategy adopted by certain cloud computing organizations is that data is secured unnecessarily in different physical zones and ordered information about the region of an organization's data is difficult to reach or not uncovered to the organizations client. This situation makes it difficult to learn whether satisfactory insurances are set up and whether legal and authoritative consistence necessities are being met. For example, NARA controls join office essentials for the limit of government records and stipulate a base height above and isolate a long way from a surge plain(Gartner, 2008).

External audits and security assertions can help this issue to some degree, yet they are not a panacea. Proper IT organization should ensure that IT assets are completed and used by settled upon methodologies and procedures; ensure that these focal points are honestly controlled and kept up; and ensure that these advantages are supporting your affiliation's framework and business goals. As described in information security, it is a condition in which an information asset is guaranteed against its order (quality or state of being free from unapproved or insecure presentation regardless of the portrayed get to rights as recorded in the passageway control list or possibly organize), trustworthiness (a quality or state of being whole/as aggregate as interesting and uncorrupted as for all intents and purposes exhibited by the hash uprightness regards) and openness (a pined for state of an information resource being open just by affirmed social occasions (as recorded in get the opportunity to control list and also network) in the desired state and at the helpful time(Anton Jola, etal. 2012).

c) Execution- Usually, CIOs are also termed CTOs (chief technology officer), thus he has the pertinent duty of executing certain improvement strategies in an organization. Due to its multi-tenant nature and resource sharing, cloud computing must moreover deal with the "clamorous neighbor" effect. This effect essentially demonstrates that in a shared establishment, the activity of a virtual machine (VM) on a neighboring focus on the same physical host may provoke extended execution degradation of the VMs in the same physical host, on account of issues, for instance, e.g. store contamination. In view of the way that the neighboring VMs may be authorized or deactivated at optional conditions, the result is an extended assortment in the real execution of cloud resources. This effect is from every angle dependent on the possibility of the applications that continually run within the VMs yet also, extraordinary elements, for instance, arranging parameters and the vigilant decision may incite enhanced errand in order to restrain the ponder (Baburajan and Rajart, 2011). Thus executive officers of organizations can also be imbibed with CIO skills which will aid the performance of the executive assignments.

d) Ensuring data minimization/Portability and interoperability: Concerning cloud computing, interoperability should be viewed as the limit of open cloud organizations, private cloud organizations, and different systems inside the endeavor to see each other's application and organization interfaces, setup, kinds of approval and endorsement, data outlines, et cetera remembering the ultimate objective to work with each other.

It is the duty of a true CIO to ensure the portability of data stores to enhance easy accessibility, handling and managing such data. Interoperability entails the ability of such data to be able to be adopted and adapted to several areas of the organization in quest of improving the organization. To defend their ability to change venders later on, offices may attempt to avoid stages or progressions that "jolt" customers into a particular thing. For example, a Treasury official cleared up that it is attempting to separate from a dealer, to some degree due to a nonappearance of detectable quality into the trader's structure and data. Interoperability can be portrayed as a measure of what amount contrasting systems or sections can participate viably. More formally, IEEE and ISO portray interoperability as the limit with regards to no less than two systems or applications to exchange information and regularly use the information that has been exchanged.

e) Absence of Resources: For quite a while, security was the primary voice of cloud computing limitation. On the mainstay currently, unavailability and insufficiency of resources to be utilized by CIOs for effective discharging of their duties is a thorn-in-the flesh of organizations wanting to improve. In 2016 nevertheless, nonattendance of benefits/ability crept ahead. Organizations are dynamically putting more workloads on cloud-IoT computing while cloud propels keep on advancing rapidly. As a result of these segments, organizations are encountering significant troubles remaining mindful of the non-available resources. In like manner, the yearning for enlarged capacity on the part of CIOs continue to be clamored for. These challenges can be restricted through additional sourcing of IT necessities most importantly, the recruitment of skilled CIO staff. A strong CIO championing cloud gathering also has any kind of effect. As Cloud Engineer, Drew Firment, puts it:

"The achievement of cloud gathering and migrations slides to your people - and the hypotheses you roll out in capacity improvement program. Until the point that the moment that you base on the main bottleneck to the flood of cloud allocation, changes made wherever else are a double dealing."

f) Cost Management: For any CIO endeavor to have an impact, it must first be able to manage available funds 
effectively and efficiently. It must try to understand that there is a lofty desire to ingest data in going from an onacquaint server user with a cloud advantage with respect to cost management. This in this manner can engage a broader seat for IT in the midst of the key masterminding process, with business accomplices arranged in both corporate and strength unit specialist positions provoking more noteworthy duty at essential authority concentrates all through the system. As new cloud considerations and new plans of activity create, CIO officials can engage a high regard talk about enabling the musings with advances, people and techniques. The Next Web depicted them as "endlessly phenomenal universes." The best refinement, which is also perceived as one of the best challenges in the RightScale consideration, is managing incurred significant damage (Netto, etal. 2018). As demonstrated by RightScale, 26 percent of respondents find cost organization as an imperative test - a number that has reliably risen each year. In 2013, only 18 percent nitty gritty issues with cost organization. As RightScale pointed out, cloud computing can offer assets openings, anyway couple of associations know how to exploit them (Mell, 2011). For the most part cloud computing can save organizational money by efficiently managing organizational income and expenditure.

\section{DISCUSSION}

\section{Competencies Of Cio}

Based on Li \& Tann's assertions in their 2013 journal of Business Research "Matching business strategy and CIO characteristics: the impact of organizational performances" highlighting the various competencies expected of the chief inspecting officer (CIO). These competencies are based upon the managerial strategy and how they in themselves influence the business performance.Below are some of the major competencies for discussion:

a). Versatile correspondence: Capacity to speak with different caliber of client in wordings that are most significant to them; conform to emergency, motivational, and open circumstances; convey the estimation of IT and advancement.

b). Catch openings: Capacity to catch openings that drive the organization's prosperity; break down and follow up on information; enhance upper hand amidst monetary, authoritative, statistic, and focused weights.

c). Change specialist: Capacity to serve past innovation as the organization's change agent, fostering versatile change and adaptability among individuals from the foundation; challenge the built up institutional culture and long-held ideal models.

d). Powerful coordinated effort and associations: Capacity to build up profitable associations with administrators, administrative boards, and inner and outer partners; politically canny.

e). Enthusiastic insight: Self-awareness, self-administration, social mindfulness, and social aptitudes. It also includes the capacity to acknowledge and follow up on input from officials, associates, and IT administration and staff.

f). Monetary administration: Capacity to oversee costs while utilizing assets for speculation and future achievement; gifted business investigations including all out cost of proprietorship, multi-year strategies for success, and rate of return.

g). Institutional standing and comprehension: Capacity to build up a solid comprehension of the establishment's chances and issues, inner and outer powers, interdependencies, projects, administrations, and voting public.

h). Operational administration: Capacity to convey accessible and solid IT administrations, including brief determination of blackouts and issues; set up operational needs; profound specialized learning in no less than one IT zone.

i). Authoritative development: Capacity to manufacture a more slender and more engaged IT association with the capacity to proactively adjust to new advances and new parts; separate authoritative storehouses and actualize consistent procedures.

j).Principled arrangement and seller administration: Capacity to assess organizations to be sourced outside the IT firms; effective bidding for compelling contracts and administration level assertions, et cetera.

k). Venture administration: Capacity to convey the key part of venture administration for institution-wide and departmental undertakings; foresee, turn away, and gain from venture disappointments; mingle the learning picked up. 1). Hazard administration: Capacity to alleviate the dangers looked by the establishment as for system and application security, data protection, administrative compliance, disaster recuperation, grounds wellbeing, and large-scale ventures.

l). Vital vision: Capacity to build up a convincing vision for building institutional accomplishment through learning of the establishment's main goal and objectives and by utilizing interests in IT and other institutional assets.

m). Confided seeing someone: Capacity to set up trust and cooperative associations with the representing board individuals, administrators, dignitaries, personnel, office heads, understudies, staff, and network individuals.

"In reality, the greater part of these is essential to the CIO without bounds."

Yet future CIOs will probably not display quality in these abilities and skills, driving a few respondents to remark on the significance of knowing one's own qualities and shortcomings, and taking care of the advancement of corresponding qualities among individuals from the CIO's staff. Another individual clarified that, "It is basic for the CIO to recognize individual qualities and shortcomings [and] procure individuals to give reciprocal aptitudes." (Almulla, 2012).

A few persons likewise noticed the nonappearance of an accentuation on specialized tasks among the things recorded and then called attention to the incongruity, that this is not the means by which current CIO position postings are depicting the position. One IT professional stated, "I am charmingly astonished, and empowered, to see next to no reference to 'innovation' foundation [in this list], in spite of the fact that that is not what I read in current places of employment declarations." This may show that the 
organization's administrators are depending on recorded desires for the CIO instead of reformulating new desires and expectations for the "new normal. "The adherence to customary capabilities for current publicized senior IT positions may mirror the requirement for the senior institutional officials to thoroughly consider the results they require from the CIO. Moreover, they may likewise need to consider how their own aptitudes and skills line up with the rundown for the future CIO (Rane, 2012). A present CIO remarked, "CIOs require [transformative] change initiative tasks. All the more vitally, other senior pioneers require these tasks, as well, for example dignitaries and VPs."

A second respondent expressed, "Every one of the abilities and skills are the same for any hired official, not only the CIO."

Rising CIO clarified the normal duties of the organizational administrators: "It's tied in with making and knowing the organization's main goal and vision, having the capacity to follow up on it, and having the validity to impart that vision and mission effectively."

Another perspective communicated the basic significance of versatile correspondence by clarifying, "You can do everything else well, however in the event that you cannot convey well, none of the rest matters." A current CIO additionally clarified that "versatile correspondence [is necessary] to impart the estimation of IT. We need to enable individuals to comprehend the contributions to the results they are searching for and enable them to comprehend the money related expenses and tradeoffs in regards to assets." These troublesome discussions likely will happen all the more oftentimes given spending weights, and the CIO is probably going to find that beforehand sufficient relational abilities should be upgraded to effectively pass on suitable messages (Lieberman, 2010).

Experienced CIOs will progressively discover the need to fortify their abilities and skills in the zones featured in this announcement to prevail in the new ordinary. Except if the CIO exhibits the capacity to lead and enhance in the bigger organizational setting, the establishment will not pick up the full supplement of its advantages from its interests in IT, and the CIO will be seen as the "boss innovation mechanic."

There are five subjects for competencies and abilities required by the effective $\mathrm{CIO}$ who wants to progress. They are:

- Basic competency of magnificence in activities and general administration

- Ability to center on the organizational mission needs and fill in as an organizational innovator

- Ability to proactively take chances to propel the establishment, as opposed to only gathering the solicitations exhibited to the IT organization

- Skill in the arrangement of contracts as administration models give new open doors in the "cloud" and between institutions

- Skill in compelling cooperation of the organization with outside accomplices to decrease duplication of administrations and related expenses, enhance efficiencies, and enhance benefit quality
It is critical to see the CIO role as a vital organizational function as opposed to just an innovative position of authority. The CIO can cultivate the appropriation of an establishment's visions and goals on the most astounding and key needs, notwithstanding featuring the capacity of data innovations to help with meeting objectives (Smith \& Mckeen, 2010). On the off chance that a viable administration structure and procedures to set up organization key-needs do not currently exist, the CIO can fill in as a backer and accomplice in setting up the way to recognize the organization's best needs. Given the monetary limitations entangling advanced knowhow, it is critical that organizations painstakingly distinguish those activities that can have the hugest effect on the organization.

The CIO who needs to be effective in the years ahead must hope to take chances to work with other departments in the establishment. Such endeavors may well prompt fortunate disclosures for development. The CIO may discover a chance to serve the organization as a "chief advancement officer" by reinforcing the stage and supporting the president or chancellor, executive, and different administrators in devising better approaches for working. CIOs who work in organizations that do not yet observe the key estimation of data advancements might need to focus on imparting the estimation of IT to the administrators in a way to catch their consideration (Almulla \& Yeob, 2016). Toward that objective, the CIO will need to focus on building associations with the officials, keeping in mind the end goal to pick up a solid understanding of their most basic challenges and vital objectives. The CIO is then better situated to skillfully weave together IT esteem with scholarly, authoritative, and co-curricular open doors in propelling the organization (Patidar, 2012).. Given the multifaceted nature of the CIO role, the future CIO may find that selecting a central innovation officer or an information officer is essential.

\section{Cloud Computing And Iot in an Organization}

Cloud enables its dynamic availability applications and system, paying little regard to region. Furthermore, quick organizational development comes to fruition in view of the technological and cognitive ability to sort out the ability to make or plan a course of action and incorporate enlisting power in help of IT and business benefits essentially more rapidly than would be possible with the present emerging organizations. Cloud computing in like manner progresses IT streamlining with the objective that IT resources are intended for most noteworthy cash sparing preferred standpoint. This is possible in light of the fact that cloud computing supports immense flexibility to deal with times of interest while keeping up a vital separation from expanded circumstances of under-utilized IT infrastructure. With its especially autonomic character, cloud computing takes out a huge piece of the time generally required to request and plan IT resources. Cloud computing also yields critical cost venture subsidizes in the land required for the server usage and furthermore power and cooling costs. Because of virtualization and the cloud's capacity of tapping resources (either through a private cloud or tapping straightforwardly open cloud resources), server homesteads can deal with the decided weight to extend their physical impression. Effective 
implementation of cloud computing and IOT in an organization might be clarified and improved as far as:

a). Adaptability: Automatic flexibility at the application level can be executed in a couple of ways. The 'going with segments' depict tremendous research, starting from system and web organizations and continuing through the nearness of Cloud Computing. Lee and Kim showed programming centered techniques for ensuring the high flexibility of organizations in Cloud Computing. [Lee and Kim, 2006] High flexibility under high organization loads does not desire anything out of pocket; it can be ensured by grasping some versatility attestation designs. The most generally perceived conventional arrangement is to simply incorporate the required resources. In any case, as they propose in the paper, diverse plans can ensure high adaptability or adaptability. They developed a web application for controlling the provisioning and de-provisioning of webserver VM (virtual machine) events, a dynamic scaling computation in perspective of critical farthest point or scaling marker of the web application [Chen and Kunz, 2016].

The scaling marker that is picked here is the amount of dynamic sessions or logon sessions in each web application. In perspective of the moving factor of the scaling pointer, a dynamic scaling figuring is used to trigger a scaling event to the provisioning subsystem. Dependent upon the revived bits of knowledge, movement to scale up or down may be begun. Scaling up or down infers that an event will be set off that educates the provisioning subsystem to start or close down web-server virtual machine events in the cloud. Exactly when the web application is scaled up, the just-started virtual machine event will run the web application. After the web application events are readied, the front-end stack balancer configuration record is then invigorated and resuscitated to place them into dynamic organizations. As indicated in advance, the scaling computation is executed in the Service Monitor sub-system, and is used to control and trigger the scale-up or down in the Provisioning sub-structure on the amount of virtual machine cases in light of the estimations of the scaling marker [Frey, Reich, etal. 2013]. A cross breed approach is used to help the two goals of benefit support on individual virtual machine events and minimization of total number of cases, as opposed to the regular approach of load modifying among available resources.

b). Dependability: Steady quality is one of the key factor to be considered in circulated computing condition. Determined quality is described as the probability that a given thing will play out its normal limit with regards to a given time allotment under a given course of action of conditions. A cloud will be more reliable if it is more accuse tolerant and more flexible to advancing conditions. It is hard to have a cloud that is absolutely free from depressions or dissatisfaction safe [Garrison, 2012]. Various types of dissatisfactions are interleaved in the conveyed computing condition, for instance, surge disillusionment, timeout frustration, resource missing dissatisfaction, orchestrate frustration, hardware frustration, programming disillusionment, and database disappointment.

The unlimited nature of the cloud computing is extraordinarily essential yet difficult to separate because cloud computing is made-up of the mix of various factors such as wide-zone frameworks, heterogeneous programming/gear parts, etc. There are various jumbled interchanges among the diverse parts of cloud computing. Along these lines, the standard quality models that are described for unadulterated programming/gear or conventional frameworks cannot be essentially associatedwith the surveying of cloud reliability [Pocatine, 2010]. The downtime of the cloud server cultivate has the negative impact on the cloud advantage steady quality. Surveying and overhauling unflinching quality in circulated computing isn't so much straightforward errand. Regardless of these, there are a couple of gadgets that are used to survey and redesign the cloud advantage constancy.

c). Security: Similar to PC security programs, cloud security incorporates a comparative general concerns: keeping up the genuineness of data, ensuring access is confined to endorse customers, and keeping up the availability of data and organizations (EDUCAUSE, 2010).

With cloud computing, the data and organizations are external to the grounds and in like manner controlling additionally, anchoring these advantages transforms into a considerably more flighty and testing proposal. Data encryption, e-disclosure, repeat and trustworthiness of data fortifications and recovery of data, the whole deal sensibility of the cloud vendor and laws with respect to limit and access to data all breeze up essential issues. It is fundamental that individual and controlled data are honestly guaranteed and that they are properly surveyed. Fratto (2009) pointed out that the security of data remains the obligation of the data proprietor/outsourcer and dispersed computing pro associations are not clearly subject for data setback or fines or other legal. Like PC security programs, cloud security incorporates a comparable general concerns. Data arranged in an open cloud and applications running in an open cloud may experience particular security exposures than would be the circumstance in an on area encouraged condition.

d). Lower costs: In cloud computing, preparing organization as an utility, and giving figuring as an organization to customers is part of the major work. One of the charming and basic cost issues in the cloud computing is the ability to pay for advantage, in perspective of necessities, avoiding the considerable expenses for PC systems buys (Armbrust, 2009). Therefore, cost ampleness is another fundamental factor direction associations should note when accepting disseminated computing. The organizations of today reliably scans for ways to deal with cut cost or extra money. Organizations need to spend a noteworthy bit of their income on the IT establishment, while less than $10 \%$ of their servers can be amazingly utilized, achieving a noteworthy abuse of money. In addition, these servers ought to be supplanted moderately at customary interims and should be kept up and administrated; extending its total cost exercises profoundly (Marston et al., 2011). Cost ideal conditions are the most grounded driver affecting IT directors' impression of SaaS openings (Benlian et. al, 2011).

e) Accessibility: High openness is, finally, the great vessel of the cloud. It embodies the likelihood of wherever and at 
whatever point access to organizations, mechanical assemblies and data and is the engaging impact of dreams of a future with associations with no physical working environments or of overall associations with completely planned and united IT systems. Openness or accessibility is in like manner related to resolute quality: an organization that is on $24 \times 7$ yet goes constantly separated is useless. As cloud organizations and applications end up being more staggering and more reliant on the shrouded cloud arrange, it winds up progressively hard quickly recognizing and dealing with issues. Burdens can rise up out of an individual organization, and also from the cooperation of different parts and motorized structures over spread frameworks and server ranches, realizing issues that put aside a long chance to be settled.

\section{Function Of Cio In Cloud And Iot Based Organizations}

Client information officer (CIO), Client data information officer (CDIO) or information technology (IT) expert, is an occupation title by and large given to the most senior official in an endeavor accountable for the regular information development and PC structures that assistance attempt targets. Routinely, the CIO reports particularly to the chief executive officer and in like manner, reply to the CEO. In military organizations, they reply to the pioneer. The Chief Information Officer part was first characterized in 1981 by William R. Synnott, past Senior Vice President of the Bank of Boston, and William H. Gruber, past teacher at the MIT Sloan School of Management. (Laplante, 2005).

IT organizations are developing. Effectively focused by and large on building and working IT establishment and robotizing business frames, CIOs are directly hunting down better ways to deal with pass on an impetus to their organizations. The present IT organization is continuously fixated on salary improvement, customer experience, and data based learning. This move is a direct result of the creating centrality of "digitization" - the use of electronic headways to redesign profitability and responsiveness, uncover bits of information about customers, upgrade, and make new arrangements of activity. The media, advancing, and retail exchange parts got digitization early, and they continue to contribute and progress. An organization with ten (10) labels to famous product units need not waste time using 10 lines of business pioneers recklessly going off in various ways. Or maybe, it needs an undeniable encompassing developmental method and vision driven by the CIO that individual pioneers can end up tied up with and adopt on the long-run. All things considered, most affiliations will use cross breed IT circumstances for a significant time allotment to come. It's the CIO's part to set general guidelines on the most proficient strategy to change customary establishment with new capacities in the cloud, in perspective of the desired outcomes the CEO needs to achieve. That is the differentiation between an enabling impact and a pioneer.

a) Change Agent-While the piece of the CIO has ceaselessly created over the earlier decades; the movements for the CIO coming to fruition out of the automated intrigue are possibly more critical and more focal than some other time in ongoing memory. The plain focus of the CIO's part
— to be particular working IT - moves dynamically into the back as endeavors try a "cloud-first" approach. On the other hand, a radical new extent of errands is being put onto the CIO's shoulders, requiring additional capacities and asking for generously more unmistakable highlight on domains, for instance, advancement or making and organizing modernized natural networks. (Gartner, 2013) With IT system twisting up progressively of a thing, CIOs will push their thought toward taking care of organizations that engage them to configure, secure and orchestrate cloud organizations from various merchants across the internet.

At whatever point perceived, CIOs have a basic motivating force to a CEO. As an official with one of just a bunch couple of far reaching points of view of the relationship through supporting business systems, they have a remarkable learning. Organizations that have had the CIO champion undertaking building are basically put to get the 'business plan'. It not simply gives the CIO full detectable quality of the affiliation's decision to-end shapes, it upgrades end customer and ICT responsibility through the consultative work-shopping of systems in transit. It gives an improved deftness and it achieves a solid foundation of end customer buy in light of the fact that all new change exercises start from a business strategy approach.

b). IT functional pioneer-The best CIOs appreciate fundamental organizing ties, setting up organizations that drive salary instead of simply passing on IT establishment like frameworks organization, servers, and limit. They work to cut through utility limits and expect control over the execution of business-fundamental applications like ERP and internet business. The profile of a compelling CIO is never again the executive of the one begin server cultivate. Imaginative aptitude alone isn't sufficient, nor is solely business insight. (Grover, 2011) The present IT pioneers must have their fingers on the beat of advancement grades and perceive how those examples may potentially drive business targets. They ought to in like manner an appreciation of how current advancement can improve proficiency and reduction costs, and additionally how it can drive efficiency.

The best IT key plans consolidate measures of accomplishment that will fill in as mile markers for progress after some time. In the present development driven business focus, in any case, those estimations should focus less on the data sources or yields IT may have used as guideposts beforehand and more on honest to goodness business comes about. "Having clear, result based key execution pointers, that is, Key Performance Indicator [KPIs] is essential," says Strock. "It is essential to ensure tight compromise with the business technique."

c) IT strategist: Most times, the cloud-computing organization is completely and thoroughly considered functional, as often as possible so far the acquiring and association of new development realization are strategized such that over- spending design, untoward techniques/procedures, etc, which can result in a tremendous unsettling influence of step-wise errands/commands is unveiled and then corrected or prevented. (Robbins \& Pappas, 2004). For example, due to more constrained cash 
related resources and confined access to splendid specific capacity when stood out from immense associations, smallsized business/associations (SMBs) are particularly tried. SMBs regularly outsource advancement organization in certainty objected to individuals to keep up and reinforce the present structure. These individuals are ordinarily grounded just in the areas of development and are not open to changing specific exercises to business functions. CIOs and their organizations should revolve around four key regions to develop a high performing IT strategy in any organizational setup. Key movement advancements and systems join private, open and creamer cloud transport models, adaptable, examination, security, dev-ops, automation, programming portrayed server ranches, blended surfaces and compartments.

To get a seat at the framework table, CIOs and the organization needs to become transversely-finished business specialist, and their supporting organizations respectively. Having a start to finish cognizance of the corporate and business unit (BU) frameworks, this enables the development to confide in business organizations over various layers of vital execution. The prerequisite for CIOs to drive business organization duty has never been more goals. For example, 35 percent of IT envisions miss the mark not because of IT, but instead by virtue of the business. Business chairmen either change needs, or wind up fair to their greatest advantage in IT's endeavors. (Path, 2007) CIOs have made the push to fathom business necessities, anyway various business directors have not reacted.

d) Technology advocate- The Technology Advocate gives specific urge grounded in the business case and uniquely crafted to address the fascinating needs of each client organization. Relationship of all sizes use advancement to coordinate business limits stretching out from direct correspondence to complex "immense data" data examination. The Technology Advocate gives client focused urge to officials and ensures quick decisions regarding development. The technology advocate is immovably related to the CIO and CTO positions at display found in greater affiliations, and by virtue of little and direct measured firms, exists as an outsourced proficient organization. Finally, the Technology Advocate gives specific incite grounded in the business case and exclusively fitted to address the uncommon needs of each client affiliation.

e) Business Strategist- Strategy has for quite a while been a noteworthy test for CIOs and their undertakings. Various CIOs and their C-level allies confer basic time and advantages for making frameworks, yet end up conveying records that collect clean on a rack. In Gartner's 2018 CIO Survey, only $23 \%$ of respondents assessed their relationship as convincing or to a great degree ground-breaking at business strategy and masterminding, and only $29 \%$ evaluated their relationship as fruitful or incredibly practical at IT system and orchestrating. (Gartner, 2018) The nonappearance of a formally recorded or clearly clarified business technique is both a significant test and an open entryway for CIOs. If the business technique has not been recorded or undeniably clarified, by then IT framework should fuse a draft of anticipated that fundamental business results would be affirmed by the activity gathering. Separate IT and business systems. At whatever point business and IT techniques are autonomous, CIOs need to exhibit the estimation of information and development. The IT method must be endeavoured with business expert, conferred and used to prompt the business framework (Hodgson and Lane, 2010).

\section{Organization Benefits In Successful Implementation Of Cloud And Iot}

Strikingly, University of Michigan Professor, Michael Grieves, first clarified electronic twins in a 2002 whitepaper. More than 10 years afterward, a couple of segments including steady accessibility, the cloud, the Internet of Things (IoT), machine learning and related abilities have centered, making it practical for organizations, all things considered, and in an extensive variety of ventures to exploit the thought he started [Chamanski and Waago, 2001]. Since we have had the ability to overcome propelled development imperatives, for instance, prohibitive data-storing and transmission limit costs, each day, a growing number of virtual twins are engaging customers to deal with the existence cycle of any methodology, thing or procedure and set up an essential base for deliberately related offerings inside the organization. Along these lines of thought, the impact of effective cloud and IoT execution of definitive execution consolidates:

a). Consumer loyalty: A productive cloud and IoT utilization empowers organizations to track most of their creation activity, thereby upgrading the effectiveness of their users who use the system. Through modifying thin unmistakable proof and quality controls, organizations can save this excess time and effort and occupy it towards various zones of their business assignments by implementing cloud and IOT. One unanticipated preferred standpoint of cloud and IoT use is consumer dedication. While your organization is using cloud and IoT respond in due order regarding upgrade all zones of its business shapes, these movements will in the long run impact the customers. Transport times can be more accurately foreseen, nearby the responsiveness of the customers while coordinating with the customers [Wamba, 2017]. If your organization's customers are equipped with strong and advantageous piece of information, they will hand-off these sureness to their customers. This, thusly, extends buyer dedication.

With the help of Oracle Service Cloud, Elsevier duplicated the amount of customers finding answers through its assistance focus focuses to $52 \%$, while the amount of request accomplishing the contact center reduced by $28 \%$. General consumer unwaveringness extended to $91 \%$. Cloud move or the demonstration of IT spending moving from customary IT offerings to cloud organizations, will impact more than $\$ 1$ trillion in IT spending by 2020, according to Gartner. Two application segments that will feel cloud move the most are business process-as-a service (BPaaS) and software-as-an service (SaaS), with a $43 \%$ and $37 \%$ specific cloud move rate. One of the primary providers of BPaaS and SaaS-based IT advantage organization answers for attempts, BMC Software, has used cloud move and more unmistakable interconnection to change the 
transport/transfer of its Digital Enterprise Management software answers for BMC delegates and customers with radically improved consumer faithfulness, decreased downtime and lower costs.

A champion among the most widely proper signs of the IoT is in its ability to empower relationship to improve the customer experience/satisfaction. In the Forbes Insights think about, $90 \%$ of executives said that a potential change to customer/purchaser satisfaction was a champion among the most basic open entryways for the IoT. While this shows up incredibly clear in the customer space, the IoT can similarly fundamentally influence how customers obtain and eat up present day outfit [Stephen, 2012]. Each one of these cases exhibits that IoT can empower any association to propel its business. Notwithstanding whether it's through creation progression, a streamlined stock system, better asset following and organization, upgraded fiscal fundamental authority or an unrivaled customer experience, the IoT can, and will continue to, improve the essential worry for associations in relatively every vertical.

b). Income: Finally, the offer of IoT-based remote monitoring and upkeep goes far past essentially decreasing organization costs; it can moreover empower organizations to dispatch absolutely new wage streams, and the extent of this open entryway is 'goliath'. Take the instance of a printing organization/firm. In the printing plant, machinebased sensors can keep the maker educated of whether there are any deficiencies along the line, empowering them to settle faults as or even before they happen. They may in like manner use sensors in a mechanical generation framework to assemble data about every movement in the creation technique, and after that analyze the data to upgrade efficiencies and diminishing bumbles. Regardless, envision a situation in which sensors are moreover placed in the printer units. The data gave by these countless would give a colossal operational and execution record of the printers. This data would empower the creator to finish three things. Immediately, it can continually enhance its things at the arrangement stage to ensure routinely point by point inadequacies are expelled. In addition, it could use the data to envision where and when issues may happen, empowering them to offer a subordinate partner organization to their customers [Beale, 2011]. Thirdly, it will gather utilized data that was at that point difficult to reach, empowering the producer to look for after new plans of activity; for example, new opportunities to charge customers for advantage if there ought to emerge an event of disillusionment, and additionally paying for utilize where advantage is by and by included. Iot-engaged remote monitoring and support empowers organizations to perseveringly pass on data from related things and distinctive points of interest for money following and making systems.

As stated, organizations can offer advancing organization contracts to screen and resolve issues. For customers without such contracts, organizations can offer extraordinarily named repair benefits through which they can make new leads for thing/advantage substitution or upgrade. For every relationship with a customer without an organization contract, successful or failed bargains tries can be fed afresh into the business' recommendations engine to extend dynamic help and refresh its business approach, ensuring things and arrangements fights better ring with customers' needs [Dobre, 2014].

c). Item conveyance: What do oil pipelines, mechanical office floors, automated stockrooms, shipping compartments and sustenance scattering centers have in like way? They're all fundamental parts in supply chains and they're all facing a key change by virtue of the Internet of Things. The Internet of Things, or IoT, has transformed into a fervently issue over the business world, to some degree in perspective of the sheer number of "things" being related over the Internet. These contraptions, be they automobiles, mechanical robots, garments washers, lifts or home indoor controllers, are being outfitted with sensors and system that engage them to create high volumes of data and transmit it over the Internet.

On the not as much as attractive end, organizations are assembling and researching that data to instruct an arrangement with respect to business decisions and undertakings. Stores organize situations, and the systems that navigate them, will be among the best beneficiaries of cloud-controlled IoT plans [Hossain, 2013]. Sensors, controllers and other IoT-related contraptions will harp on everything from particular things to containers and transportation holders. They will be introduced all through assembling plants and stockrooms and will help track naval forces of vessels, trucks and distinctive vehicles.

All in all, these varying and interconnected components will give managers consistent, end-to-end detectable quality and control over their supply chains and thing transport. Layer on data driven computerization, gigantic data examination, wherever/at whatever point cloud-based organizations and other essential advances, and store arrange frames are set to twist up significantly more ground-breaking, obvious and cost-profitable. Clearly, picking up by the ability of the IoT requires mindful organizing and incorporates taking care of a grouping of challenges. Regardless, various associations in an extent of industry divisions are presently accepting prizes from IoT-enabled supply chains [Hassan, 2013]. Given the present pace of inventive change, and the impetus to use propelled advances to switch developed plans of activity and assignments, associations need to move right now to start modernizing their supply chains with IoT-driven courses of action. Various types of supply chains may see more conspicuous or lesser profitability gets, yet IoT-engaged game plans should drive enormous changes in thing transport, profitability, viability and other key execution markers paying little regard to the store arrange class.

In the Forbes Insights survey, $64 \%$ of overseers said that the general organization of the store arrange was a requirement for their organization. For organizations with sprawling coordination errands, this shows up extremely clear. Amazon, for example, has experienced speedy advancement in the past couple of years. It starting at now manages in excess of 500 million stock keeping units (SKUs) (up from 400 million earlier this year) and works more than 490 fulfillment centers, focuses and diverse zones the world over, some of which are in excess of 1 million square feet in district. Amazon laborers used to walk around these colossal fulfillment centers, checking and picking things [Prakash, 
2015]. Regardless, in 2012, Amazon acquired Kiva Systems, which makes IoT-engaged robots that are by and by used to motorize that methodology. By upgrading dispersion focus profitability; these robots have cut working expenses by $20 \%$, saving a normal $\$ 22$ million reliably in each. If the Kiva robots were presented all around, at all of Amazon's assessed 255 dissemination centers, it could save the association more than $\$ 5$ billion consistently while in like manner ensuring that thing transport is pleasant.

d). Item quality: Brian Buntz quickly records instances of organizations who are executing or profiting by IoT limits. Each delineation demonstrates how IoT is reshaping or renaming industry sharpens. One case incredibly convincing is Proactive Quality Assurance, enabled by game plan of identifying and assessing devices in fundamental zones all through the store system and age process.

IoT sensors assemble add up to thing data and other untouchable syndicated data from various periods of a thing cycle. This data relates to the course of action of unrefined materials used, temperature and work environment, misuses, the impact of transportation et cetera on the last things. What's more, if used as a piece of the last thing, the IoT device can give data about the customer conclusions on using the thing. These wellsprings of information can later be dismembered to recognize and cure quality issues. With IoT, the ability to screen and analyze process and thing quality at fundamental concentrations in the store system and age shapes, and recognize when sub-standard materials are introduced or thing attributes get sidetracked from points of interest ensures critical cost diminishes [Marusic, 2013].

Consider situations where upgraded checking of arrangements, manufacturing frames, and even things being used by customers can add to improved thing and process quality. In any case, IBM has for a long while been a professional of proactive quality organization, developing the Quality Early Warning System (QEWS) estimations for earlier, more definitive acknowledgment of issues every through it possess creation arrange. The QEWS computations have been joined into the IBM Prescriptive Quality on Cloud offering to empower creators to perceive issues in supplier materials and also in progress techniques.

e). Profit: The cloud computing is in a state of advance. New business and age models, industry standards, best practices, and advancement have enabled best performing makers to segregate themselves from whatever is left of the pack. To help creating change and give a phase to headway, notable producers have grasped a movement of advancements, including cloud, examination, and the Internet of Things.

The result is an ability to join smart motorization with examination, engaging a more moneymaking and productive gathering condition. Nevertheless, for a few makers consolidating these movements into consistent assignments has exhibited troublesome. As the software foundation for collecting accomplishment, Enterprise Resource Planning (ERP) courses of action are the trademark fit for empowering these key changes [Rao, 2012]. In a present report, manufacturers were asked for to show their best two goals for the coming year. Clearly, profitability is the genuine driving part of a maker; that will never hint at change. Regardless, what are changing in collecting are the methods by which affiliations are getting to that profitability. The bigger goal of any business is to make a profit, and cutting operational expenses wherever possible can massively influence that target. The best preferred standpoint of moving to the cloud is clearly a budgetary one. The fiscal model related with the cloud is obvious and judicious [Ranjan, 2015]. There are no candid costs, level rate month to month charge per customer and measure of information exchange limit used, and straightforward versatility in either heading.

The study found that 88 percent of cloud customers demonstrated cost hold stores and 56 percent of respondents agreed that cloud organizations have helped them bolster profits. Besides, 60 percent of respondents said cloud computing has diminished the necessity for their IT organizations to take care of system, giving them greater chance to revolve around procedure and advancement. In addition, without a doubt, 62 percent of the organizations that have saved money are reinvesting those hold subsidizes again into the business to extend headcount, bolster wages and drive thing advancement [Perere, 2013]. The study shows precisely what a basic impact cloud computing is having on U.K. in addition, U.S. organizations, Engates said. It's particularly entrancing that, paying little heed to the ceaseless money related foundation, half of associations on the two sides of "the lake" are truly extending profits and building up their business utilizing the cloud. This consolidates placing assets into headcount and compensation and what's more driving further improvement.

\section{CONCLUSION, RECOMMENDATIONS \& FUTURE WORK}

Most importantly $\mathrm{CIO}$ as a senior level supervisor requires key, business and administrative skills. A CIO ought to have great generally speaking comprehension of IT, yet the key is the capacity to lead and oversee IT authorities' deliberately right way for the association. Those skills vary from the abilities required for IT authorities, in this manner making such vocation way very difficult. This exploration has commonsense pertinence for enlistment and advancement of CIOs. Business understanding and vital administration skills ought to be joined into advancement programs for potential CIO's. This exploration was finished by dissecting sentiments of specialists who are or were satisfying the part of CIO.

It may be helpful to break down the required capabilities likewise by examining the sentiments of non-CIOs for instance CEO's or by dissecting the competency relationship with real execution of CIOs. Use of "positioning inquiry" approach in the competency displaying is an exceptionally helpful approach. Finance related administration skills as one of the abilities for examination ought to be incorporated into a survey for future investigation. This would approve and comprehend positioning of the budgetary administration information among different skills required for a CIO. This review gives a confirmation which loans support to figuring out what are the key occupation works in the part of the CIO in the present and future business condition. It additionally distinguishes abilities and competencies basic for the CIO to be effective in driving development and aggressiveness by 
utilizing ICT in the present business condition and clarifies why these are essential.

The proof displayed in the outcomes segment demonstrates that the global CIO part has moved far from the customary innovation administration part and moved towards a more key part. To be fruitful, the CIO needs a decent comprehension of the business as a key leader, and needs great relational abilities at all levels in the organization and be capable communicate viably with business customers. The $\mathrm{CIO}$ needs to comprehend the business at all levels and have the capacity to work together with others as this is basic for conveyance and dealing with the ICT frameworks and infrastructure as ICT presently penetrates all level of associations. IT managers additionally are observing their business to be much more difficult than before in light of the fact that they, as well, are being solicited to create aptitude outside from their conventional zone of specialized quality. Regardless of whether they aren't really moving to build up their nontechnical abilities for their own vocation ways, IT managers progressively are being requested to think and act like the business partners they bolster. This is especially valid as organizations receive IT techniques grasping "out-frastructure" through distributed computing, virtualization and Web administrations. Brilliant CIOs and senior IT officials have started to grasp the test to guarantee key arrangement amongst IT and business objectives. Through a mix of preparing, proceeding with training, coaching programs and just embedding's themselves into more business exchanges among their nonspecialized official companions, those chiefs are stepping forward. In any case, this and other research information shows that the best CIOs - and actually, fruitful IT organizations as a rule - should push the limits of their abilities into a new region on the off chance that they will live up to their organizations' desires of IT's an incentive to the primary concern.

\section{REFERENCES}

[1] Buttenberg, K. (2017). Measuring Business Performance in Young Firms.

[2] Chamanski, A., \&Waag $\varnothing$, S. J. (2001). Organizational performance of technology-based firms-the role of technology and business strategies. Enterprise and innovation management Studies, 2(3), 205223.

[3] Wamba, Samuel Fosso, AngappaGunasekaran, ShahriarAkter, Steven Ji-fan Ren, Rameshwar Dubey, and Stephen J. Childe. "Big data analytics and firm performance: Effects of dynamic capabilities." Journal of Business Research 70 (2017): 356-365.

[4] Freeman, M., \& Beale, P. (1992, March). Measuring project success. Project Management Institute.

[5] S.C.B. Intelligence, (2008) Disruptive civil technologies, in: Six Technologies with Potential Impacts on US Interests Out to 2025.

[6] C. Dobre, F. Xhafa, (2014) "Intelligent services for big data science", Future GenerationComputer Systems. 37 267-281.

[7] L. Yan, Y. Zhang, L.T. Yang, H. Ning, (2008) "The Internet of Things: From RFID to theNext-Generation Pervasive Networked Systems", CRC Press.

[8] A. Alamri, W.S. Ansari, M.M. Hassan, M.S. Hossain, A. Alelaiwi, M.A. Hossain, (2013)"A survey on sensor-Cloud: architecture, applications, and approaches", Int. J. Distrib.Sens. Netw.

[9] J. Gubbi, R. Buyya, S. Marusic, M. Palaniswami (2013) 'Internet of Things (IoT): Avision, architectural elements, and future directions', Future Generation ComputerSystems, Vol. 29 No. 7, pp.1645 - 1660.

[10] N. Alhakbani, M.M. Hassan, M.A. Hossain, M. Alnuem, (2014), "A framework ofadaptive interaction support in Cloud-based Internet of Things (IoT) environment", in:Internet and Distributed Computing Systems, Springer, pp. 136-146.
[11] S.K. Dash, S. Mohapatra, P.K. Pattnaik, (2010), "A survey on application of wirelesssensor network using Cloud computing", Int. J. Comput. Sci. Eng. Technol. 1 (4) 50-55.

[12] B.P. Rao, P. Saluia, N. Sharma, A. Mittal, S.V. Sharma, (2012), "Cloud computing forInternet of Things \& sensing based applications", in: Sensing Technology (ICST), SixthInternational Conference on, IEEE, 2012, pp. 374-380.

[13] A. Zaslavsky, C. Perera, D. Georgakopoulos, (2013), "Sensing as a service and big data".ArXiv Preprint arXiv:1301.0159.

[14] P. Prakash Jayaraman, K. Mitra, S. Saguna, T. Shah, D. Georgakopoulos, R. Ranjan,(2015)"Orchestrating Quality of Service in the Cloud of Things Ecosystem", Volume 128 - No.7

[15] Gottschalk, P. (Ed.). (2006). CIO and Corporate Strategic Management: Changing Role of CIO to CEO: Changing Role of CIO to CEO. IGI Global.

[16] Laplante, P. A., \& Bain, D. M. (2005). The changing role of the CIO: Why IT still matters. IT Professional Magazine, 7(3), 45

[17] Carter, M., Grover, V., \& Thatcher, J. B. (2011). The emerging CIO role of business technology strategist. MIS Quarterly Executive, $10(1)$.

[18] Lane, M. S., \&Koronios, A. (2007). Critical competencies required for the role of the modern CIO. ACIS 2007 Proceedings, 90.

[19] Hodgson, L., \& Lane, M. S. (2010). What are the key job functions and critical competencies required for the role of the CIO in achieving superior organizational performance?. Issues in Informing Science and Information Technology, vol 7, 257-266.

[20] Robbins, S., \& Pappas, A. (2004). Within and Beyond: Understanding the Role of the CIO. CIO wisdom: Best practices from silicon valley's leading IT experts, 1 .

[21] Elkin, D. (2012). The strategic CIO: The change advocate. CIO, (Mar/Apr 2012), 10

[22] Von Simson, Ernest. "The new role of the CIO". ww.businessweek.com. Retrieved 13 May 2018.

[23] Lawry, Rachel; Waddell, Dianne; Singh, Mohini (2007). "Roles, Responsibilities and Futures of Chief Information Officers (CIOs) in the Public Sector" (PDF): 3. Retrieved 14 May 2018.

[24] Peppard, Joe (August 2010). "Unlocking the Performance of the Chief Information Officer (CIO)". California Management Review. 52 (4): 5. Retrieved 14 May 2018.

[25] Manwani, Sharm; Flint, David. "From manager to chief information officer". www.computerweekly.com. Retrieved 26 October 2014.

[26] Chen, Y., \& Kunz, T. (2016, April). Performance evaluation of IoT protocols under a constrained wireless access network. In Selected Topics in Mobile \& Wireless Networking (MoWNeT), 2016 International Conference on (pp. 1-7). IEEE.

[27] Collinchau. (2013, August 19). 7 performance metrics for measuring cloud ROI within HP Cloud Management. Micro Focus. Retrieved 19 February 2018 from https://community.softwaregrp.com/t5/ITOperations-Management-ITOM/7-performance-metrics-formeasuring-cloud-ROI-within-HP-Cloud/ba-p/300699\#.Wopi1INua01

[28] Frey, S., Reich, C., \&Lüthje, C. (2013, September). Key performance indicators for cloud computing SLAs. In The Fifth International Conference on Emerging Network Intelligence, EMERGING (pp. 60-64).

[29] Garrison, G., Kim, S., \& Wakefield, R. L. (2012). Success factors for deploying cloud computing. Communications of the ACM, 55(9), 6268.

[30] Hwang, G., Lee, J., Park, J., \& Chang, T. W. (2017). Developing performance measurement system for Internet of Things and smart factory environment. International Journal of Production Research, 55(9), 2590-2602.

[31] Iosup, A., Ostermann, S., Yigitbasi, M. N., Prodan, R., Fahringer, T., \&Epema, D. (2011). Performance analysis of cloud computing services for many-tasks scientific computing. IEEE Transactions on Parallel and Distributed systems, 22(6), 931-945.

[32] The cloud service industry's 10 most critical metrics. Guiding Metrics. Retrieved 19 February 2018 from https://guidingmetrics.com/content/cloud-services-industrys-10most-critical-metrics/

[33] Pocatilu, P., Alecu, F., \&Vetrici, M. (2010). Measuring the efficiency of cloud computing for e-learning systems. Wseas transactions on computers, 9(1), 42-51.

[34] Deka Ganesh Chandra \& Dutta Borah Malaya, (2012), Role of Cloud Computing in Education, ICCEET, Pg: 832-836.

[35] Dong, B., Zheng, Q., Qiao, M., Shu, J., \& Yang, J. (2009). BlueSky cloud framework: an e-learning framework embracing cloud 
computing. In Cloud Computing (pp. 577-582). Springer Berlin Heidelberg.

[36] Faisal A. Alshuwaier, Abdullah A. Alshwaier, Ali M. Areshey (2011), Applications of Cloud Computing in Education.

[37] Feng, D. G., Zhang, M., Zhang, Y., \& Xu, Z. (2011). Study on cloud computing security. Journal of Software, 22(1), 71-83.

[38] Fox, A., Griffith, R., Joseph, A., Katz, R., Konwinski, A., Lee, G., .. \&Stoica, I. (2009). Above the clouds: A Berkeley view of cloud computing. Dept. Electrical Eng. and Comput. Sciences, University of California, Berkeley, Rep. UCB/EECS, 28, 13.

[39] Hailu, A. (2012). Factors influencing cloud-computing technology adoption in developing countries (Doctoral dissertation, Capella University).

[40] Lee, I., \& Lee, K. (2015). The Internet of Things (IoT): Applications, investments, and challenges for enterprises. Business Horizons, 58(4), 431-440.

[41] Gubbi, J., Buyya, R., Marusic, S., \&Palaniswami, M. (2013). Internet of Things (IoT): A vision, architectural elements, and future directions. Future generation computer systems, 29(7), 1645-1660.

[42] Botta, A., De Donato, W., Persico, V., \&Pescapé, A. (2016) Integration of cloud computing and internet of things: a survey. Future Generation Computer Systems, 56, 684-700.

[43] Parwekar, P. (2011, September). From internet of things towards cloud of things. In Computer and Communication Technology (ICCCT), 2011 2nd International Conference on(pp. 329-333). IEEE.

[44] Motahari-Nezhad, H. R., Stephenson, B., \&Singhal, S. (2009) Outsourcing business to cloud computing services: Opportunities and challenges. IEEE Internet Computing, 10(4), 1-17.

[45] Choubey, R., Dubey, R., \&Bhattacharjee, J. (2011). A survey on cloud computing security, challenges and threats. International Journal on Computer Science and Engineering (IJCSE), 3(3), 1227 1231.

[46] Varbanov, R. (2011). Challenges and risks in companies' transition to cloud computing.
[47] Aazam, M., Khan, I., Alsaffar, A. A., \& Huh, E. N. (2014, January). Cloud of Things: Integrating Internet of Things and cloud computing and the issues involved. In Applied Sciences and Technology (IBCAST), 2014 11th International Bhurban Conference on (pp. 414419). IEEE.

[48] Velusamy, Kaushik, DeepthiVenkitaramanan, Shriram K. Vasudevan, Prakash Periasamy, and Balachandran Arumugam. "Internet of things in cloud." Journal of Engineering and Applied Sciences 8, no. 9 (2013): 304-13.

[49] Millard, Christopher (2013). Cloud Computing Law. Oxford University Press. ISBN 978-0-19-967168-7.

[50] Singh, Jatinder; Powles, Julia; Pasquier, Thomas; Bacon, Jean (July 2015). "Data Flow Management and Compliance in Cloud Computing". IEEE Cloud Computing. 2 (4):2432. doi:10.1109/MCC.2015.69

[51] Netto, M.; Calheiros, R.; Rodrigues, E.; Cunha, R.; Buyya, R. (2018). "HPC Cloud for Scientific and Business Applications: Taxonomy, Vision, and Research Challenges". ACM Computing Surveys. 51 (1): $8: 1-8: 29$. doi: $10.1145 / 3150224$

[52] Marston, Sean; Li, Zhi; Bandyopadhyay, Subhajyoti; Zhang, Juheng; Ghalsasi, Anand (2011-04-01). "Cloud computing - The business perspective". Decision Support Systems.51(1): 176189. doi:10.1016/j.dss.2010.12.006

[53] Rochwerger, B.; Breitgand, D.; Levy, E.; Galis, A.; Nagin, K.; Llorente, I. M.; Montero, R.; Wolfsthal, Y.; Elmroth, E.; Caceres, J.; Ben-Yehuda, M.; Emmerich, W.; Galan, F. "The Reservoir model and architecture for open federated cloud computing". IBM Journal of Research and Development. 53 (4):4:14:11. doi: 10.1147/JRD.2009.5429058

[54] Baburajan, Rajani (2011-08-24). "The Rising Cloud Storage Market Opportunity Strengthens Vendors". It.tmcnet.com. Retrieved 201805-11. 